\title{
Las homilías Adversus Iudaeos de Juan Crisóstomo: temas y estrategias argumentativas polémicas
}

\author{
John Chrysostom's Adversus Iudaeos homilies: topics and \\ polemic argumentative estrategies
}

\author{
Andrea Simonassi Lyon \\ andreasimonassilyon@gmail.com \\ Universidad de Buenos Aires / CONICET. Instituto \\ Multidisciplinario de Historia y Ciencias Humanas, \\ Argentina
}

Recepción: 13 Marzo 2020 Aprobación: 22 Junio 2020 Publicación: 22 Septiembre 2021

Cita sugerida: Simonassi Lyon, A. (2021). Las homilías Adversus Iudaeos de Juan Crisóstomo: temas y estrategias argumentativas polémicas. Sociedades Precapitalistas, 11, e064. https://doi.org/10.24215/22505121e064
Resumen: Mientras fue presbítero de Antioquía entre 386 y 398 -año en que fue nombrado Patriarca de Constantinopla-, Juan Crisóstomo, representante del cristianismo niceno, tuvo una prolífica carrera como predicador en las iglesias más importantes de la ciudad. Fue conocido como "boca de oro" por sus dotes en retórica y son muchas las obras homiléticas que se adjudican a su período antioqueno, entre las que podemos citar su serie conocida como Adversus Iudaeos. Pronunciada entre los años 386 y 387, tiene como objeto atacar a aquellos cristianos que participan de festividades judías y asisten a la sinagoga. Pero no son sólo ellos los que sufrirán el embate del presbítero: a lo largo de su serie, vemos cómo arremete contra los judíos, la Sinagoga, la Ley mosaica y las fiestas judías. El presente artículo se propone rastrear y discutir los epítetos y críticas pronunciados por Crisóstomo en las homilías Adversus Iudaeos en contra de los judíos y sus principales instituciones y festividades, así como contra aquellos miembros de su congregación que compartían, asistían a y participaban de sus fiestas, y recurrían a los "especialistas en lo sagrado" judíos para obtener curas o solucionar problemas.

Palabras clave: Judíos, Cristianos, Judaizantes, Sinagoga, Ley.

Abstract: While he was presbyter of Antioch between 386 and 398 -year in which he was elected Patriarch of Constantinople-, John Chrysostom, who represented the Nicene Christianity, had a prolific career as a preacher in the most important churches of the city. He was known as "Golden Mouth" because of his rhetorical skills and many homilies are awarded to his antiochene period, among which we can mention his series known as Adversus Iudaeos. Pronounced between 386 and 387, it aims to attack those Christians who participate in Jewish rites and attend the synagogue. But not only them will suffer the onslaught of the priest: throughout his homilies, he goes after the Jews, the synagogue, the Mosaic Law and Jewish festivities. This article aims to track and discuss the epithets and criticisms pronounced by Chrysostom in the Adversus Iudaeos homilies against the Jews, their main institutions and festivities, as well as against those members of his congregation who shared, attended and participated in their parties and turned to the Jewish "specialists in the sacred" to obtain cures or solve problems.

Keywords: Jews, Christians, Judaizers, Sinagogue, Law. 


\section{Introducción}

Entre 386 y 387 d.C. Juan Crisóstomo, presbítero de Antioquía, pronunció ocho homilías en contra de los judíos. ${ }^{1}$ Estas respondían a una situación recurrente hacia fines del siglo IV en dicha ciudad: una intensa interacción religiosa que difuminaba las fronteras religiosas que Crisóstomo intentaba imponer. Varios miembros de su audiencia -a los que acusaba de "judaizantes"2 participaban de festividades judías, acudían y ponderaban a la sinagoga y a sus líderes religiosos, y respetaban a los hebreos por ser el pueblo de las Sagradas Escrituras. Con la intención de desprestigiar a estos y a sus instituciones, Crisóstomo comenzó con su prédica antijudía, que terminaría cristalizando en la serie homilética que hoy conocemos como Adversus Iudaeos.

El propósito de este artículo es relevar y discutir las críticas y epítetos que el futuro Patriarca de Constantinopla pronuncia en contra de los judíos, sus principales instituciones, rituales y festividades.

\section{Antioquía de Siria}

Antioquía contaba con una sólida comunidad judía no sólo en la ciudad propiamente dicha, sino también en las afueras, hacia el noreste en la zona rural y en los suburbios del sur, en Dafne. Aquí, precisamente, se encontraba la Cueva de Matrona, ${ }^{3}$ lugar donde se pensaba que estaban enterrados los mártires macabeos y que era un importante centro de culto judío que atraía a ciertos feligreses cristianos. Antioquía contaba con dos sinagogas: una en la ciudad, en el barrio judío - Kerateion-, y otra en Dafne. Dicha comunidad ejercía una gran influencia en la vida urbana, y varios de sus eran miembros parte del aparato burocrático imperial, por lo que la interacción cotidiana era algo habitual. ${ }^{4}$

El cristianismo, por su parte, contó con el apoyo imperial a partir de la conversión de Constantino. El siglo IV es testigo de un gran número de conversiones al cristianismo y, al mismo tiempo, de una amplia gama de obras arquitectónicas que reflejan la importancia que había adquirido en Antioquía. Gran cantidad de iglesias aparecen en el escenario urbano, como la Gran Iglesia Dorada iniciada por Constantino y finalizada por Constancio, el Santuario de Babilas construido por Melecio, obispo de dicha ciudad, y la Iglesia de los Macabeos (Mayer y Allen, 2012).

El siglo IV se configura, asimismo, como un momento en el cual varios grupos religiosos compiten por la preeminencia y el favor imperial. Antioquía ofrecía una amplia gama de opciones religiosas que competían entre sí por ser dominantes: arrianos, nicenos y "griegos". Juan Crisóstomo representaba a uno de los grupos cristianos que pugnaban en esa competencia: los nicenos. Pero también este grupo sufre una escisión y entonces son dos los obispos nicenos que buscan imponerse: Paulino y Melecio. Hacia 380, el Cunctos Populos de Teodosio estableció el cristianismo niceno como religión de Estado, lo que aceleró la victoria de la facción nicena de Melecio, que logró dominar la escena políticoreligiosa de la ciudad. ${ }^{6}$ 


\section{Homilías Adversus Iudaeos ${ }^{7}$}

Entre fines de agosto y principios de septiembre de 386 y mediados de septiembre de 387, Juan Crisóstomo pronunció su serie homilética conocida como Adversus Iudaeos. Se trata de ocho homilías en las que se dedica a atacar al pueblo judío, sus instituciones y festividades más relevantes. La razón que brindó el presbítero para dar inicio a la serie fue la gran cantidad de cristianos que participaban de las festividades, ayunos, rituales e, incluso, que asistían a la sinagoga, a los que acusó de “judaizantes”.

Sus exhortaciones tenían como objetivo delimitar la comunidad cristiana oponiéndola a "otros" no cristianos -y cristianos no nicenos-, a fin de evitar que su congregación siguiese confraternizando con los que él consideraba "enemigos" de la cristiandad, en este caso los judíos.

Las Adversus Iudaeos se configuraron no sólo como un ataque a aquellos que transgredían -judaizantes- o se encontraban por fuera -los judíos- de los confines de la cristiandad, sino que también fueron un recurso utilizado para delinear el comportamiento que un "verdadero" cristiano -para Crisóstomo, aquellos que se ceñían a los lineamientos nicenos- debía llevar adelante. La identidad religiosa excluyente que profesaba Crisóstomo estaba lejos de ser la que practicaban muchos de sus fieles. Varios interactuaban con judíos, asistían a la sinagoga y acudían a "especialistas en lo sagrado" judíos -ya sea para resolver conflictos o para acceder a curaciones, entre otras razones-. Asimismo, asistían a la iglesia, practicaban los ritos cristianos y esto no reflejaba una contradicción para ellos. A la hora de definir qué era ser cristiano, Crisóstomo se dio a la tarea de especificar qué debían o no debían hacer los verdaderos seguidores de Cristo, a dónde podían asistir y a dónde no, y qué debían creer y qué no.

Al intentar reafirmar la identidad cristiana en oposición a la judía y a la griega, Crisóstomo opera sobre prácticas preexistentes que daban cuenta de la interacción entre distintos grupos religiosos. Esta situación es inaceptable para el presbítero antioqueno porque difumina las fronteras que quería establecer. Así, los destinatarios de la serie Adversus Iudaeos serán los, por él llamados, judaizantes: personas que se consideraban cristianos pero que habían traspasado las fronteras de la cristiandad como él las entendía por participar de festividades hebreas y por interactuar con aquellos que se configuraban como "otros", los judíos. La mayoría no veía la religión como lo hacían hombres como Crisóstomo, quienes sostenían que la identidad y la lealtad religiosas debían permear todos los aspectos de la vida y que debían prevalecer por sobre otras identidades, como la cívica, la política o la étnica (Sandwell, 2007).

La identidad religiosa no sólo era determinada por la creencia interna sino también por la praxis cotidiana. La identidad cristiana debía demostrarse en todo momento, debía desplegarse visualmente. Por eso, la asistencia a lugares no cristianos, la práctica de rituales no cristianos, la celebración de fiestas no cristianas eran comportamientos que un "verdadero cristiano" no tendría.

Debemos volver a subrayar que el contexto político religioso de Antioquía no puede desligarse de esta situación. Si bien el grupo niceno había logrado prevalecer sobre el resto de las opciones religiosas de la ciudad, esto no quiere decir que no debía reforzar contantemente su lugar de predominio. Sostendremos, entonces, que Juan Crisóstomo desarrollará su serie Adversus Iudaeos con el fin de 
desprestigiar a los otros grupos religiosos que se configuraban como competencia; y uno de esos grupos eran los judíos.

Hacia fines de agosto de 386, ante la inminencia de Rosh Hashanná (Año Nuevo) y Yom Kippur (Día del Perdón), Crisóstomo decide interrumpir la serie contra los anomeos que venía desarrollando y dar paso a una nueva en contra de los judíos, pues previó que varios de los miembros de su congregación participarían de tales festividades:

(...) los festivales de los lamentables y miserables judíos pronto marcharán sobre nosotros y en rápida sucesión; la fiesta de las Trompetas, la fiesta de los Tabernáculos, los ayunos. (...) mis discursos contra los anomeos pueden posponerse para otra ocasión, y el aplazamiento no causará daño $\left(A d v\right.$. Jud. 1, I, 3-4). ${ }^{8}$

Son varios los temas que trata Crisóstomo a lo largo de su serie. Los judíos, los judaizantes, la sinagoga, el ayuno, la vigilancia entre feligreses, la circuncisión son algunos de los más recurrentes a lo largo de las Adversus Iudaeos. En este trabajo nos proponemos exponer y analizar aquellos que consideramos más relevantes para el análisis de la serie homilética.

\section{A. Los judios}

Como ya hemos adelantado, Antioquía era una ciudad que contaba con una ecléctica composición religiosa y el judaísmo gozaba de una alta estima entre los habitantes de dicho rincón del Imperio por su vinculación con los judíos del Antiguo Testamento. Asimismo, no eran percibidos como "otros" o diferentes. Siguiendo los lineamientos teóricos de Shaye Cohen: "the Diaspora Jews of antiquity were not easily recognizable -if, indeed, they were recognizable at all” (Cohen, 1999, p. 67). De hecho, el autor subraya:

(...) the boundary between Jews and gentiles in antiquity was not always clearly marked; the degree of social interaction between Jews and non-Jews was sufficiently great that it was not always easy to tell who was a Jew and who was not (Cohen, 1999, p. 341).

Los judíos de Antioquía, si bien vivían en un barrio específico en la ciudad el Kerateion-, festejaban públicamente, en la calle, recibiendo a todos aquellos no judíos con intenciones de participar (Kelly, 1995). Algunos sólo permanecían como espectadores mientras que otros tomaban parte activa en los festejos (Ziadé, 2007).

Era necesario desacreditar a los judíos, desprestigiarlos a fin de que fueran percibidos como un otro diferente del cristiano. Es imperativo subrayar que la construcción de la identidad cristiana como una identidad excluyente y que debía demostrarse y ser visible no era algo que primara en el común de la congregación del presbítero. De hecho, Sandwell (2007) remarca que Crisóstomo construye identidades fijas. Había que ser cristiano y no había espacio para la ambigüedad, ya que la identidad debía demostrarse en todas las acciones y aspectos de la vida (Sandwell, 2007, p. 6). Era preciso definir qué era ser cristiano y qué era ser judío, y configurarlos como opuestos. Así, en su primera homilía describe a los judíos como "miserables y duros" (athlioi kai talaipôrôn; Adv. Jud. 1, II, 5). Los judíos habían rechazado las bendiciones del cielo, a diferencia de los cristianos:

Cuando tantas bendiciones desde el cielo llegaron a sus manos, las dejaron a un lado (...). El Sol de la Justicia de la mañana surgió para ellos, pero ellos rechazaron sus rayos y se sentaron en la oscuridad. Nosotros que fuimos alimentados por la 
oscuridad, trajimos la luz hacia nosotros y fuimos liberados de la penumbra de su error. Ellos fueron las ramas de la raíz sagrada, pero esas ramas se rompieron. (...) Desde su infancia leyeron a los profetas, pero crucificaron a aquel que predijeron los profetas. (...) son miserables [athlíoi] porque rechazaron los bienes [agathá] que les fueron enviados mientras que otros tomaron estos bienes y los atrajeron hacia sí mismos. Aunque esos judíos fueron llamados hijos, cayeron en parentesco con perros; nosotros que éramos perros recibimos la fuerza, a través de la gracia de Dios, para dejar a un lado la irracional naturaleza que era nuestra y elevarnos al honor de hijos (Adv. Jud. 1, II, 5).

Los judíos son, además, duros de cuello y por eso destruyeron el yugo y quedaron fuera del Reino de los Cielos. Crisóstomo subraya que esto es un crimen que cometerían únicamente bestias salvajes:

Pero, ¿cuál es la fuente de su dureza? Viene de la glotonería y alcoholismo (...) Cuando los animales brutos se alimentan de un pesebre lleno, se vuelven gordos y se vuelven más obstinados y difíciles de controlar; no soportan ni el yugo, ni las riendas ni la mano del auriga. Así los judíos fueron conducidos por su borrachera y glotonería al mal supremo; patearon, rechazaron el yugo de Cristo ( $A d v$. Jud. 1, II, 8).

Ellos [los judíos] viven para sus vientres, se quedan boquiabiertos por las cosas de este mundo, su condición no es mejor que la de cerdos o cabras debido a sus formas insensibles y excesiva glotonería. Sólo saben una cosa: llenar sus vientres y alcoholizarse (...) (Adv. Jud. 1, IV, 14).

Pero no eran sólo bestias salvajes y duros de cuello por su obstinación y glotonería. Crisóstomo los compara, asimismo, con terneros salvajes que no sirven para el trabajo sino sólo para ser sacrificados ( $A d v$. Jud. 1, II, 8). Además, eran impíos, indecentes, crueles e inhumanos ( $A d v$. Jud. 1, VI, 24-25). Otra de sus características, según Crisóstomo, es que son demonios y que los demonios habitan sus almas. Al ser demonios, se convierten en asesinos porque "Si el diablo es un asesino, es claro que los demonios que lo sirven son asesinos también" ( $A d v$. Jud. 8, VIII, 236).

¿Ves que los demonios habitan sus almas y que estos demonios son más peligrosos que los de antaño? Y esto es muy razonable. En los viejos días los judíos actuaban impíamente hacia los profetas; ahora indignan al Maestro de los profetas ¿No te estremeces por ir al mismo lugar con hombres poseídos, que tienen muchos espíritus inmundos, que han sido criados en medio de matanzas y derramamiento de sangre? ¿Debes compartir un saludo con ellos e intercambiar una palabra? ¿No debes alejarte de ellos ya que son la desgracia e infección común de todo el mundo? ¿No han llegado a toda forma de maldad? (...) Sacrificaron a sus propios hijos e hijas a los demonios. Se rehusaron a reconocer la naturaleza, se olvidaron de los dolores de parto, pisotearon la crianza de sus hijos, volcaron de sus cimientos las leyes de parentesco, se volvieron más salvajes que las bestias salvajes ( $A d v$. Jud. 1, VI, 24-25).

En su afán por delimitar la identidad cristiana, el presbítero se asigna la tarea de identificar "otros" diferentes y errados. Otros que no son cristianos y que se oponen a estos. Etiquetar es una parte del proceso de construcción identitaria y la identidad no se construye de forma aislada sino en contraste con otra. En este sentido, Juan Crisóstomo no puede edificar la identidad cristiana para su audiencia sin hacer referencia constante a lo que era ser "griego" o judío. Pero así como utiliza etiquetas específicas, en numerosas ocasiones recurre a unas generales que englobaban a todos aquellos que no pertenecían a la cristiandad, sin diferenciar a sus "enemigos", asimilándolos como "no creyentes", "impíos" o "idólatras". "Entonces la impiedad de los judíos y los paganos está a la par", 
manifiesta Crisóstomo en su primera homilía ( $A d v$. Jud. 1, VI, 23). No había diferencias entre ellos porque todos estaban equivocados y tanto los "griegos" como los anomeos y los judíos compartían una debilidad de pensamiento según el presbítero: sostener que Cristo había sido sólo un hombre ( $A d v$.Jud. 5, III, 106).

(...) como la impiedad de los anomeos es similar a la de los judíos, mi presente conflicto es similar al anterior. Y hay una similitud porque los judíos y los anomeos hacen la misma acusación. ¿YY qué cargos hacen los judíos? Que Él llamó Dios a su propio Padre y se hizo a sí mismo igual a Dios. Los anomeos también hacen este cargo (...) (Adv. Jud. 1, I, 4).

Citando como autoridad a Jesús, Crisóstomo sostiene que los judíos no adoran a Dios:

“¡Ningún judío adora a Dios!” ¿Quién lo dice? El Hijo de Dios lo dice. Porque dijo: "Si conoces a mi Padre, me conoces a mí. Pero no me conocen ni a mí ni a mi Padre". ¿Puedo tener un testigo más digno de confianza que el Hijo de Dios? ( $A d v$. Jud. 1, III, 11).

Crisóstomo se rehúsa a permitir que exista interacción entre los cristianos y los no cristianos. Un verdadero cristiano no debe compartir, participar ni relacionarse con otros no cristianos -incluyendo aquellas facciones cristianas no nicenas-.

La diferencia entre los judíos y nosotros no es una pequeña, ¿verdad? (...) ¿de modo que crees que las dos religiones son realmente una y la misma? ¿Por qué mezclas lo que no puede mezclarse? Ellos crucificaron a Cristo, a quien adoras como Dios. ¿Ves cuán grande es la diferencia? ¿Cómo es, entonces, que sigues corriendo hacia aquellos que mataron a Cristo cuando dices que adoras a aquel a quien crucificaron? ( $A d v$. Jud. 4, III, 78-79).

Crisóstomo hace uso de la figura del deicidio, lugar común previamente utilizado por los Padres de los siglos III y IV para argumentar contra el judaísmo. ${ }^{9}$ $\mathrm{Y}$, de hecho, en reiteradas ocasiones asegura que los judíos fueron abandonados por Dios por haber masacrado a su hijo. Todas las penurias que atravesaron y atraviesan son consecuencia de su mayor pecado: "Mataron a Cristo, levantaron violentamente las manos contra el Maestro, derramaron su preciosa sangre. Es por eso que no tienen posibilidad de expiación, excusa o defensa" (Adv. Jud. 6, II, 154).

B. Los judaizantes

El principal destinatario de las Adversus Iudaeos es "el judaizante". Robert Wilken (1983) distingue entre "judaizantes cristianos" y "cristianos judíos". Los primeros son aquellos cristianos que adoptan ciertos aspectos de la Ley mosaica. Los segundos son judíos que creen en Jesús pero que siguen observando la Ley. Ahora bien, lo que plantea el autor es que esta diferenciación esconde el hecho de que la marca distintiva de ambas categorías es la misma: la observancia de la Ley judía. "In contrast to the Arians or the Gnostics, the distinctive characteristic of Judaizers was not teaching or doctrine, but observance" (Wilken, 1983, p. 70).

El foco del ataque de los líderes cristianos no eran los "judíos cristianos", pues estos eran, a lo sumo, un problema de la comunidad judía. ${ }^{10}$ En cambio, los judaizantes eran miembros de la Iglesia y eran, para los hombres como Crisóstomo, elementos disruptivos de la comunidad cristiana y causaban divisiones en su interior. Su mera existencia ponía en cuestionamiento la idea 
de un otro judío errado, obstinado y deicida que Crisóstomo sostenía. Wilken (1983) argumenta que los judaizantes, al observar aspectos de la Ley judía y celebrar sus festivales con ellos, significaban una especie de reto teológico: si observaban los rituales judíos como divinos, la legitimidad de los ritos cristianos se vería discutida. De todas maneras, sostiene el autor, el debate que encarna Crisóstomo con estos cristianos judaizantes no se centra tanto en la materia teológica en el sentido estricto de la palabra, sino más bien en términos de praxis, en materia de observancia de los rituales judíos (Wilken, 1983, p. 75).

\footnotetext{
Porque cuando ven que ustedes, que adoran al Cristo a quien crucificaron, siguen con entusiasmo su ritual, ¿cómo pueden dejar de pensar que los ritos que han realizado son los mejores y que nuestras ceremonias no valen nada? Porque después de venerar y adorar nuestros misterios, corren hacia los mismos hombres que destruyen nuestros ritos (Adv. Jud. 1, V, 20).

¿Qué gran acto de locura y desorden sería tomar como socios en los festivales a los que han sido deshonrados, a los que Dios ha abandonado, los que han enojado al maestro? Dime esto. Si un hombre hubiese asesinado a tu hijo, ¿soportarías admirarlo o aceptar su saludo? ¿No lo rechazarías como un demonio malvado, como el demonio mismo? Mataron al Hijo de tu Señor; ¿tienes la osadía de entrar con ellos bajo el mismo techo? (Adv. Jud. 1, VII, 28).
}

Crisóstomo considera a los judaizantes como una enfermedad que debe ser erradicada del cuerpo de la Iglesia y que él debe combatir a partir de la palabra: "Otra enfermedad grave exige cualquier cura que puedan traer mi lengua, una enfermedad que se ha implantado en el cuerpo de la Iglesia” ( $A d v$. Jud. 1, I, 3).

Pero ahora que los festivales judíos se acercan y están cerca y en la puerta, si no curamos a aquellos que están enfermos de las cosas judías [tô̂s de ton ioudaiká nosoûntas], temo que, debido a su asociación inadecuada y su profunda ignorancia, algunos cristianos puedan participar en las transgresiones (...) Porque si no escuchan ninguna palabra de mi parte hoy, se unirán a los judíos en sus ayunos; una vez que hayan cometido este pecado, será inútil de mi parte aplicar el remedio ( $A d v$. Jud. 1, I, 4).

En varias ocasiones, el presbítero antioqueno se proclama como un médico que debe hacer frente a esta enfermedad: "Los mejores médicos primero apagan el fuego de la fiebre y luego curan las heridas y fracturas" ( $A d v$. Jud. 3, II, 53). Como todo buen médico, debe prevenir y sabe que la inminencia de los festivales judíos atraerá a los "débiles" -como los llama reiteradamente-.

Ahora bien, es interesante remarcar la utilización de la metáfora del cuerpo que Crisóstomo toma de la carta de San Pablo a los Corintios (1 Cor.12:12-27) Es una metáfora bien conocida para un auditorio que tiene cierto conocimiento sobre las Sagradas Escrituras. Por el hecho de estar erigiendo la identidad cristiana, necesita establecer una frontera clara: ellos y nosotros. El "nosotros" forma parte de un todo, un cuerpo, el cuerpo de la Iglesia, y el judaizante amenaza ese todo, lo desmiembra. Intenta generar un sentimiento de comunidad, de pertenencia, haciendo referencia a su audiencia como "hermanos" para enfatizar ese "nosotros". En este sentido, llamar en sus homilías a sus fieles como hermanos o vecinos, la utilización de la metáfora del cuerpo de la Iglesia para generar un ideal de unidad, de igualdad, tratar a los judaizantes como una enfermedad que justamente está atentando contra ese cuerpo, que amenaza con destruirlo, son mecanismos que utiliza para lograrlo. Una de las cuestiones más reveladoras al 
respecto es la advertencia a aquellos que, si bien no participan de los ritos judíos, no denuncian a los cristianos que sí lo hacen:

\begin{abstract}
¿Te resulta una carga opresiva denunciar a quienes cometen estos pecados? Es una carga opresiva permanecer en silencio. Porque este silencio te convierte en enemigo de Dios y te destruye tanto a ti que ocultas a esos pecadores como a aquellos cuyos pecados no se revelan (...) tu silencio hará de Dios tu enemigo y lastimará a tu hermano; si lo denuncias y revelas su pecado, harás que Dios sea propicio y beneficie a tu hermano, y ganarás como amigo a alguien que ha enloquecido pero que aprendió por experiencia que le serviste bien ( $A d v$. Jud. 1, VIII, 32).
\end{abstract}

Además de vigilar y denunciar a aquellos que padezcan la enfermedad judaizante, a Crisóstomo le preocupa que la congregación no haga efectivo lo oído durante el sermón y por esto exhorta a que mediten y pongan en práctica lo que han escuchado en la liturgia:

(...) mi propósito al hablar no es que escuchen esto para ustedes mismos; quiero que también trabajen en curar a aquellos con esta enfermedad (...) No está en cuestión que, cuando vengan a la iglesia, escuchen lo que se dice; estás abierto a la condena cuando fallas en seguir con la acción a las palabras que escuchas ( $A d v$.Jud. 8, IX, 238).

Para llevar adelante su lucha contra los judaizantes, Crisóstomo se ve en la obligación de desprestigiar aquellos lugares, prácticas, rituales, festividades -y a la misma comunidad judía, como venimos analizando- en las cuales participan los fieles "afectados por el error".

C. La sinagoga y las fiestas

Un aspecto importante del ataque de Crisóstomo en la serie en contra de los judíos lo configura el lugar. Había locaciones que se asociaban directamente a los judíos y que los cristianos debían evitar: la sinagoga, el santuario curativo conocido como Cueva de Matrona y las fiestas judías.

Christine Shepardson (2014) demuestra que Crisóstomo tenía un ideal cristiano que distinguía prácticas apropiadas de aquellas que no lo eran: griegas y judías. Así, hace uso de una retórica en clave espacial con el fin de especificar a qué lugares podía asistirse y qué lugares debían evitarse. En este sentido, el teatro, los templos, la sinagoga y las festividades judías eran lugares y prácticas moralmente peligrosas, y Crisóstomo recurre a la retórica para modificar la manera en que su audiencia veía estos sitios. Para Crisóstomo, la identidad individual estaba intrínsecamente unida a cuestiones de espacialidad y así conjuga una geografía imaginaria, redefiniendo lugares geográficos a través de la lente de la ortodoxia nicena (Shepardson, 2014, p. 104). Intenta manipular aquellos lugares que se configuran como competencia, asignándoles connotaciones negativas y asociándolos a un estado de impureza. La misma impureza puede ser adquirida por quienes concurran a ellos. En su sexta homilía, Crisóstomo pregunta: “¿No tienen miedo de poner un pie dentro de un lugar profano e impuro [bebêlous kai akathártous]?" (Adv. Jud. 6, VI, 170).

Leonard Rutgers (2010) realiza un aporte significativo a la hora de estudiar la sinagoga en los escritos patrísticos. El autor observa que hay una tendencia a no considerar ya el término "sinagoga" como una institución concreta ubicada en tiempo y espacio sino que más bien se lo priva de su historicidad y especificidad y pasa a ser un término abstracto, genérico, al que se le infunden nuevos significados. Se convierte no sólo en sinónimo de todo el pueblo judío sino también de todo lo malo y despreciable (Rutgers, 2010, p. 456). Deja de ser 
un lugar real para convertirse en la esencia del mal y en la némesis de la Iglesia (Rutgers, 2010, p. 464).

Esto lo notamos en la primera de las homilías de la serie. Crisóstomo realiza un ataque directo a la sinagoga, catalogándola de "escondite de ladrones"; "guarida de animales salvajes"; "guarida de un animal sucio"; "lugar abandonado por Dios"; "vivienda de demonios" (Adv.Jud. 1, III, 10-11).

¿Qué nombre digno podemos encontrar para llamar a sus sinagogas? (...) un burdel, una fortaleza del pecado, un lugar de alojamiento para demonios, una fortaleza del demonio, la destrucción del alma, el precipicio y el pozo de toda perdición, o cualquier otro nombre que le des (Adv. Jud. 6, VII, 174).

A su vez, en la octava homilía vuelve a enfatizar la idea de que la sinagoga es un lugar maligno y se pregunta:
¿Cómo puedes ir a la sinagoga? Si haces la señal de la cruz, el poder maligno que habita en la sinagoga se aleja [he ponerá dynamis he tên synagôgên oikoûsa]. Pero si no haces la señal de la cruz, enseguida pones tus armas en las puertas. Encontrándote desnudo y desarmado, el diablo te afligirá con innumerables males. Pero ¿por qué insistimos en decir estas cosas? Es aparente, por el modo en que entras en la sinagoga, que te das cuenta de que es un terrible pecado ingresar en ese malvado lugar [eis to ponerón ekeîno khôrion]. Estás ansioso porque no te hayan visto ingresar, y les pides a tus sirvientes, amigos y vecinos que no les digan nada a los sacerdotes (...) (Adv. Jud. 8, VIII, 237).

Asimismo, lo que hace Crisóstomo es equiparar la sinagoga al templo pagano: "Si han ignorado al Padre, si han crucificado al Hijo, y han rechazado al Espíritu, ¿uno no podría declarar que la sinagoga es una morada de demonios [tôn daimônôn katagôgion einai ton tópon]? Dios no es adorado allí. En cambio, es un lugar de idolatría [all'eidôlolatreías ekeîno to khôrion loipón estin]" (Adv. Jud. 1, III, 11).

Crisóstomo compara la sinagoga con la Iglesia, con el fin de dejar en claro que la Iglesia es una institución superior y superadora. Lo que repite el presbítero en sus homilías es que la Ley judía ha quedado obsoleta desde la venida de Cristo. Por ende, la Iglesia es ahora la institución de culto por excelencia y la sinagoga ha perdido, desde la venida, su lugar de relevancia.

En más de una ocasión, Crisóstomo hace referencia a que Dios no se encuentra en la sinagoga y esto hace que sea un lugar habitado por demonios: "Cuando Dios abandona a una persona, ¿qué esperanza de salvación queda? Cuando Dios abandona un lugar, ese lugar se convierte en morada de los demonios" ( $A d v$. Jud. 1, III, 11).

Uno de los elementos que le conferían una valoración positiva a la sinagoga era que contenía en su interior las Sagradas Escrituras. Ahora bien, Crisóstomo se encarga de desestimar esto advirtiendo que ellas no le confieren su sacralidad al lugar que las contiene.

¿Y hacia dónde vas? ¿Donde el Padre es insultado? ¿Donde el Hijo está cubierto de blasfemia? ¿Dónde el Espíritu Santo y el Vivificador son despreciados? Pero ¿no tienes miedo (...) cuando entras en lugares sucios e insalubres? (...) No me digas que allí está la Ley y están los libros de los profetas: esto no es suficiente para hacer un lugar sagrado. (...) Entonces respóndeme: si el diablo fuera a recitar las Sagradas Escrituras, ¿por qué su boca se volvería santa? No puedes decirlo, un demonio sería lo que es: un demonio (Adv. Jud. 6, VI, 136-137). 
Sandwell (2007) sostiene que Crisóstomo intenta hacer prevalecer la vida religiosa por sobre la civil. Intenta que el ser cristiano sea la faceta identitaria más relevante de cada individuo. Así, utiliza lugares de la ciudad para dar cuenta del desprestigio de la sinagoga. En varias de sus homilías la compara con el teatro, asegurando que no es mejor que este.

[Los judíos] reúnen chusma, afeminados y prostitutas, y arrastran la multitud del teatro y a los actores a la sinagoga. No hay diferencia entre el teatro y la sinagoga. Sé que algunos me condenan por osar decir que la sinagoga no es diferente del teatro, pero les respondo que es audaz de parte de ellos no estar de acuerdo con lo que digo (...). La sinagoga no es mejor que el teatro" ( $A d v$. Jud. 1, II-III, 9-10).

A lo largo de la serie, varias veces hace referencia a que la sinagoga es un "burdel" y "una casa de prostitución". Asimismo, sostiene que la sinagoga es menos honorable que una posada "porque no es solamente un lugar de reunión para ladrones y vendedores ambulantes sino también para demonios" ( $A d v$. Jud. $1, \mathrm{IV}, 15)$.

Otro lugar que se encarga de desacreditar es la Cueva de Matrona. Configurado como un santuario curativo, varios cristianos asisten allí a fin de obtener la cura a ciertas enfermedades que los aquejan. Crisóstomo considera este lugar tan profano como el templo de Apolo, y los asimila. Vuelve, entonces, a sostener que la impiedad de los judíos y de los paganos es la misma.

Aunque no hay un ídolo allí [en la sinagoga], los demonios habitan el lugar. Y digo esto no sólo de la sinagoga aquí en la ciudad sino también de la de Dafne; porque en Dafne hay un lugar perverso, de perdición, que llaman Matrona (...) Para mí, el santuario de Matrona y el templo de Apolo son igual de profanos (Adv. Jud. 1, VI, 23).

Los festivales y fiestas judías, asimismo, deben evitarse. Así como los judaizantes se configuran como una enfermedad dentro del cuerpo de la Iglesia, los festivales judíos también lo son. Pero estos no sólo aparecen en la serie como una enfermedad. Crisóstomo se refiere también a ellos como espacios donde se desarrolla la inmoralidad y donde habitan los demonios ( $A d v$. Jud. 2, III, 44).

¿Qué enfermedad es esta? Los festivales de los lamentables y miserables judíos (...) hay muchos en nuestras filas que dicen que piensan como nosotros. Sin embargo, algunos de ellos van a ver los festivales y otros se unirán a los judíos para festejar y ayunar (Adv. Jud. 1, I, 4).

Pero ahora que el diablo convoca a sus esposas a la fiesta de las Trompetas (...) dejan que se enreden en acusaciones de impiedad, dejan que se vean arrastradas a formas licenciosas.

Porque, por regla general, son las rameras, los afeminados y todo el coro del teatro quienes se apresuran a ese festival ( $A d v$. Jud. 2, III, 44).

\section{La Ley}

En su segunda homilía, Crisóstomo ataca el tiempo en que se lleva adelante la praxis de la Ley mosaica. No acomete directamente contra la Ley porque, al haber sido entregada por Dios, le concede el mismo grado de divinidad que a la cristiana. Pero arremete contra el momento en que se lleva adelante una observancia de la Ley. La Ley, luego de la venida de Cristo y de la destrucción del Templo de Jerusalén, ha quedado obsoleta. Por ende, aquellos que continúan observándola son obstinados, según el presbítero, y caen en la desgracia, alejándose de la salvación por la gracia que opera a partir de la venida de Jesús. 
No decimos esto en contra de la Ley. ¡El Cielo lo prohíba! (...) porque la Ley no es contraria a Cristo. ¿Cómo podría serlo, cuando la Ley nos lleva a Él? Pero nos vemos forzados a decir estas cosas por la controversia con aquellos que no usan la Ley como deberían. Los que ultrajan la Ley son aquellos que nos piden que nos separemos de ella de una vez y vayamos a Cristo, y luego nos dicen que nos aferremos nuevamente. La Ley ha beneficiado nuestra naturaleza. Estoy de acuerdo en eso y nunca lo voy a negar. Pero ustedes, judaizantes, se aferran a ella más allá del tiempo adecuado y no nos dejan ver lo útil que ha sido. Porque la Ley (...) ha preparado nuestra alma para recibir una filosofía mejor. La Ley ha beneficiado nuestra naturaleza, pero sólo si nos guía sinceramente hacia Cristo. Si este no es el caso, nos ha hecho daño al privarnos de las cosas más grandes ( $A d v$. Jud. 2, II, 41-42).

Son dos los elementos de la Ley que son desarrollados en esta homilía por el presbítero: el ayuno y la circuncisión. El primero es catalogado de "malvado", "sucio" y una "enfermedad". Afirma que, aunque es un ayuno, no por eso es menos abominable, ya que se realiza en contra del propósito de Dios. En su tercera homilía, Crisóstomo contrasta el ayuno judío con el cristiano y llega a la conclusión de que el ayuno cristiano es, por supuesto, el correcto, por el motivo por el cual se lo practica: el arrepentimiento de los pecados. En cambio, el ayuno judío es llevado a cabo únicamente por respetar una fecha.

¿No sabes que una [Pesaj] es un tipo [typos], y la otra, en cambio, la verdad [alêtheia]? Pues escucha la gran diferencia. La pascua [judía] evitó la muerte corporal, mientras que la otra sofocó la ira de Dios contra el mundo entero; una liberó a los judíos de Egipto, mientras que la otra nos liberó de la idolatría; la Pascua [judía] ahogó al Faraón, pero la Pascua [cristiana] ahogó al diablo; después de la Pascua [judía] vino Palestina, pero después de Pascua vendrá el cielo (Adv. Jud. 3, VI, 68-69).

La circuncisión también es atacada con vehemencia por el presbítero, especialmente en la segunda homilía de la serie. Lo que critica principalmente es su condición de vetusta. Si los hombres se circuncidan ahora, luego de la existencia del nuevo pacto con Dios, entonces hace daño, porque responde a mera terquedad. La venida "cancela" la circuncisión, al igual que la Ley; se vuelve arcaica, responde al antiguo pacto que ha sido reemplazado por uno nuevo y superador.

Y alguien podría decir: “¿Hace tanto daño la circuncisión que hace que todo el plan de redención de Cristo sea inútil?” Sí, el daño de la circuncisión es tan grande como eso, no por su propia naturaleza sino por su obstinación. Hubo un tiempo en que la Ley era útil y necesaria, pero ahora ha cesado y es infructuosa. Si te circuncidas ahora, cuando el tiempo ya no es el correcto, esto hace el regalo de Dios inútil. Es porque no estás dispuesto a venir a Él que Cristo no te será de ninguna ventaja ( $A d v$. Jud. 2, I, 37).

En su cuarta homilía aborda el tema de la Pascua y por qué no debe festejarse la pascua de los judíos: "La Ley ordenaba que la Pascua se celebrara el primer mes y en Jerusalén, en un momento determinado y en un lugar determinado" ( $A d v$. Jud. 4 , IV , 81). Haciendo referencia a que Jerusalén ya no está en manos de los judíos y a la destrucción del Templo, Crisóstomo sostiene que se quebranta lo que Dios ha encomendado al festejar la Pascua en otro lugar y en otro momento que los mandados por el Señor. Invalida, entonces, el ritual judío por la destrucción del Templo (Sandwell, 2007, p. 141).

Como no puede ir en contra del Dios de los judíos por ser el mismo que el de los cristianos, Crisóstomo presenta a los judíos desobedeciendo la voluntad de Dios 
porque continúan respetando una Ley que ya ha dejado de tener injerencia. Luego del advenimiento de Cristo se ha establecido un nuevo pacto y, por ende, para el presbítero los judíos son obstinados por seguir respetando algo que ha quedado obsoleto. Los elementos en los que se basaba la Ley, el Templo de Jerusalén y el sacerdocio judío, han sido destruidos:

¿No ves que la Ley saca su fuerza del lugar? Y como la ciudad ya no está, ya no puede haber sacerdocio. No puede haber emperador si no hay ejército, ni púrpura, ni corona, ni nada que constituya la monarquía, por lo que no puede haber sacerdote donde el sacrificio sea abolido, oblaciones prohibidas, objetos sagrados profanos, suprimido todo recurso; el sacerdocio consistía en todo esto ( $A d v$. Jud. 7, II, 182).

Citando a Pablo, para darle autoridad a su exhortación, enfatiza la desaparición del sacerdocio judío, que fue reemplazado por uno más sublime:

De todo esto, está claro que ese sacerdocio ha terminado, que ha sido reemplazado por otro mejor y más elevado. Es decir, es necesario saber que debe introducirse un nuevo tipo de vida, conforme a este nuevo sacerdocio y a una mejor ley, que es la nuestra. Pablo declara esto cuando dice: "(...) el sacerdocio ha cambiado, también la ley debe ser cambiada (...)" (Adv. Jud. 7, V, 198).

Así, Crisóstomo desestima la Ley judía y el sacerdocio de Israel, que gozaban de alta estima, al igual que el pueblo judío, por ser la referencia del Antiguo Testamento (Sandwell, 2007). La Ley, luego de la venida, entonces, queda obsoleta y luego de la destrucción del Templo de Jerusalén el sacerdocio de Israel ha desaparecido y ha sido reemplazado por uno nuevo y mejor, que es el sacerdocio espiritual cristiano.

\section{Conclusión}

La serie homilética Adversus Iudaeos se configura como un elemento que le permite a Juan Crisóstomo delinear la identidad cristiana de corte niceno que pretendía imponer en sus audiencias. Lo que el presbítero intentaba impartir eran las doctrinas y dogmas que respondían al ideal niceno. Debido a la situación política descripta al inicio de este artículo, que cuestionaba permanentemente el poderío de este grupo religioso en Antioquía a fines del siglo IV, fue necesario embarcarse en la tarea de establecer qué era ser cristiano y qué comportamientos, qué praxis lo configuraban, y que la identidad religiosa debía primar sobre cualquier otra - política, cívica, etc.-. En un momento, como ese final de siglo, en el que varias eran las opciones religiosas que una persona podía elegir, el nicenismo se atribuyó la tarea de definir las fronteras de la cristiandad y todo aquel que no respondía a los cánones establecidos era tildado de "enemigo", de "errado", de "otro". Un "otro" con el cual no había que mantener contacto. El problema que encontraron los hombres como Crisóstomo fue la existencia de estos judaizantes que ponían en jaque todo el sistema identitario definido, estático, fijado. Como afirma en su trabajo Isabella Sandwell (2010), los hombres de Iglesia como Crisóstomo tenían una visión de la identidad como algo estrictamente definido. Pero esto no era percibido así por sus audiencias. Más bien, lo que se da es una apropiación más laxa de la identidad religiosa. No generaba una contradicción para un miembro de la audiencia del presbítero antioqueno ir el sábado a la sinagoga y, el día siguiente, a la iglesia. 


\section{Referencias}

Cohen, S. (1999). The Beginnings of Jewishness: Boundaries, Varieties, Uncertainties. Berkeley: University of California Press.

Downey, G. (1961). A History of Antioch in Syria from Seleucus to the Arab Conquest. Princeton: Princeton University Press.

Foerster, R. (ed.) (1906). Bibliotheca Scriptorum Graecorum et Romanorum Teubneriana. Libanii Opera, vol III: Orationes XXVI-L. Leipzig: B.G. Teubneri.

Geerard, M. (1974). Clavis Patrum Graecorum, volumen II, ab Athanasio ad Chrysostomum. Turnhout: Brepols.

Harkins, P. (trad.) (1979). Discourses against Judaizing Christians (The Fathers of the Church, Volume 68). Washington D. C.: Catholic University of America Press.

Kelly, J.N.D. (1995). Golden Mouth. The story of John Chrysostom - Ascetic, Preacher, Bishop. Ithaca-Nueva York: Cornell University Press.

Mayer, W. y Allen, P. (2012). The Churches of Syrian Antioch (300-638 BE). Leuven París-Walpole: Peeters.

Meeks, W. y Wilken, R. (1978). Jews and Christians in Antioch in the first four centuries of the Common Era. Missoula: Society of Biblical Literature.

Pradels, W., Brändle, R. y Heimgartner, M. (2006). The Sequence of Dating of the Series of John Chrysostom's Eight Discourses Adversus Iudaeos. Zeitschrift für Antikes Christentum / Journal of Ancient Christianity, 6(1), 90-116. Doi: https://doi.org /10.1515/zach.2002.013

Rajak, T. (2016). The Fourth Book of Maccabees in a Multi-cultural City. En Y. Furstenberg(Ed.),Jewish and Christian Communal Identities in the Roman World (pp. 134-150). Leiden - Boston: Brill.

Rutgers, L. (2010). The synagogue as a foe in Early Christian Literature. En Z. Weiss (Ed.), "Follow the Wise": Studies in Jewish History and Culture in Honor of Lee I. Levine (pp. 449-468). Lago Winona: Eisenbrauns.

Sandwell, I. (2007). Religious identity in Late Antiquity. Greeks, Jews and Christians in Antioch. Nueva York: Cambridge University Press.

Sandwell, I. (2010). John Chrysostom's audiences and his accusations of religious laxity. En D. Gwynn y S. Bangert (Eds.), Late Antique Archaeology. Vol. 6. Religious Diversity in Late Antiquity (pp. 523-542). Leiden - Boston: Brill.

Shepardson, C. (2014). Controlling Contested Places: Late Antique in Antioch and the Spatial Politics of Religious Controversy. Berkeley-Los Angeles-Londres: University of California Press.

Stroumsa, G. (1996). From Anti-Judaism to Antisemitism in Early Christianity?. En O. Limor y G. Stroumsa (Eds.), Contra Iudaeos. Ancient and Medieval Polemics between Christians and Jews (pp. 1-26). Tübingen: Mohr.

Wilken, R. (1983). John Chrysostom and the Jews. Rethoric and Reality in the late 4th century. Berkeley: University of California Press.

Ziadé, R. (2007). Les Martyrs Maccabées: del'histoire juive au culte chrétien. Les homélies de Grégoire de Nazianze et de Jean Chrysostome. Leiden-Boston: Brill. 
Notas

1 Si bien la serie es conocida como "contra los judíos", nos parece pertinente distinguir entre el título, que fue atribuido a la serie posteriormente por la tradición, y el objeto de las homilías, que son aquellos cristianos que participan de las festividades judías.

2 En la serie aparece el verbo ioudaizô [Clavis Patrum Graecorum (CPG) 48, p. 934].

3 Actualmente se cuestiona que el lugar de enterramiento de los macabeos sea efectivamente la Cueva de Matrona. De todas maneras, el debate continúa abierto (Rajak, 2016).

4 Desde la epigrafía se comprueba la existencia de judíos en la región. Las excavaciones desarrolladas durante la década de 1930 no fueron muy fructíferas debido a que el emplazamiento de la ciudad antigua está ocupado por la ciudad actual (Downey, 1961, p. 28). De todas maneras, excavaciones en otros lugares permiten dar un panorama de las comunidades judías del siglo IV en la región. En Apamea -ciudad a 50 millas de Antioquía- fue hallado un piso de mosaico con inscripciones que dan cuenta de aquellos que habían contribuido para su construcción. Entre ellos destacan judíos de Antioquía. Asimismo, esta familia que realizó la donación de mosaicos poseía una tumba en Beth She'arim, necrópolis de la zona de Galilea. Meeks y Wilken (1978) hacen hincapié en la existencia de una inscripción en Tiberíades que menciona judíos en Antioquía y también en la de una inscripción en Apamea que se refiere a un ministro judío de Antioquía (Meeks y Wilken, 1978, p. 53). También, a partir de la correspondencia entre Libanio y el patriarca judío Gamaliel VI puede constatarse la presencia de judíos en Antioquía de Siria que, a su vez, se encontraban integrados en la ciudad, compartían el idioma -griego- y eran, como en el caso de Gamaliel VI, considerados un igual. Desde la comunicación epistolar de ambos, se comprueba que el patriarca envía a su hijo a estudiar con Libanio, maestro de retórica clásica -y maestro de Crisóstomo antes de su ingreso a la Iglesia-. En las Oraciones de Libanio encontramos referencias a judíos que trabajaban en sus tierras. De ellas se infiere que existían judíos de condición pobre, sin tierras (Or. 47, en Bibliotheca Scriptorum Graecorum et Romanorum Teubneriana. Libanii Opera.). Wilken (1983) considera que esta situación de pobreza no estaba extendida entre la población judía de la región y habla de una diversidad de actividades económicas practicadas por ella. También subraya que varios miembros del consejo de la ciudad eran judíos. En su trabajo expone que en las ciudades del este la comunidad judía estaba gobernada por un consejo compuesto por representantes de varias sinagogas y dirigido por un gerusiarca. La tumba de uno de ellos, Edesio, fue hallada en Beth She' arim (Wilken, 1983).

5 Así denomina Crisóstomo a los seguidores de la religio grecorromana.

6 Cabe aclarar que, de todas maneras, se encontraban en permanente conflicto con otros grupos cristianos y no cristianos que cuestionaban su dominio y poder.

$7 \quad$ Siguiendo los lineamientos de Wendy Pradels, Rudolf Brandle y Martin Heimgartner (2002), el orden cronológico de la serie sería 1, 3, 4, 2, 5, 6, 7, 8. Gracias a la referencia que hace Crisóstomo en su homilía 6 al Motín de las Estatuas ocurrido en febrero de 387, pudieron datarse las homilías 4, 5, 6, 7 y 8, pronunciadas en el otoño de 387. En cuanto a la homilía 1, tuvo lugar un año antes, en septiembre de 386, debido a que la homilía 4 comienza estableciendo que "De nuevo los judíos (...) van a ayunar, y nuevamente debemos asegurar el rebaño de Cristo" ( $A d v$. Jud. 4, I, 71). En cuanto a la homilía 3, se ha convenido en situarla entre las homilías 1 y 4 . De hecho, no se había publicado como integrante de la serie hasta que fue insertada por Bernard de Montfaucon y parte de la historiografía ha manifestado que no pertenecería a ella. Los autores sostienen que la homilía 5 fue pronunciada en Yom Kippur (en 387, celebrado el 9 y 10 de septiembre); por eso la toman como referencia para datar el resto de la serie. En la homilía 2, la inmediatamente anterior a la 5, Crisóstomo dice que el próximo servicio será el mismo día del ayuno. Así, la homilía 4, que asegura que "el ayuno tendrá lugar en 10 días o más" ( $A d v$. Jud. 4. I, 72), la fechan el 29 de agosto. En la homilía 2 se menciona que Yom Kippur será en cinco días, por lo que los autores sostienen que fue pronunciada el 5 de septiembre. Tomando aún como referencia la homilía 5, la que sigue es la 6 y lo sostienen por la manera en que Crisóstomo la comienza: "Ven que mi voz 
está débil y no puede durar por mucho tiempo" ( $A d v$. Jud. 6, I, 148), a consecuencia del largo sermón pronunciado el día anterior, por lo que la fechan el 10 de septiembre. La homilía 7 comienza con una alusión a la fiesta de los Tabernáculos, en la que se observa que está pronta a llevarse a cabo. Así, los autores la sitúan en una fecha cercana al 12 de septiembre. La homilía 8 fue pronunciada una semana después de la 7 , por lo que se la fecha el 19 de septiembre.

8 Las traducciones son propias, desde CPG 4320. Una buena traducción al inglés, en Harkins (1979).

9 Stroumsa (1996, p. 7) asegura que el deicidio aparece formulado hacia el siglo II.

10 Así como los cristianos judíos eran rechazados por los hombres de la Iglesia, lo mismo puede decirse de los judíos cristianos por parte de la comunidad judía. 